\title{
Protective versus pathogenic anti-CD4 immunity: insights from the study of natural resistance to HIV infection Samuele E Burastero*1, Mariangela Figini² ${ }^{2}$ Barbara Frigerio, Paolo Lusso ${ }^{3}$, Luca Mollica ${ }^{4}$ and Lucia Lopalco ${ }^{5}$
}

\begin{abstract}
Address: ${ }^{1}$ Unit of Clinical and Molecular Allergy, Division of Immunology, Infectious Diseases and Transplants, San Raffaele Scientific Institute, 58, via Olgettina, Milan, 20132, Italy, ${ }^{2}$ Unit of Molecular Therapies, Department of Experimental Oncology and Laboratories, Fondazione IRCCS National Institute of Tumor, 1, via Venezian, Milan, 20132, Italy, ${ }^{3}$ Laboratory of Immunoregulation, National Institute of Allergy and Infectious Diseases, National Institute of Health, Bethesda, MD 20892, USA, ${ }^{4}$ Biomolecular NMR Laboratory, Dulbecco Telethon Institute, San Raffaele Scientific Institute, 58, via Olgettina, Milan, 20132, Italy and ${ }^{5}$ Unit of Immunobiology of HIV, Division of Immunology, Infectious Diseases and Transplants, San Raffaele Scientific Institute, 58, via Olgettina, Milan, 20132, Italy

Email: Samuele E Burastero* - s.burastero@hsr.it; Mariangela Figini - mariangela.figini@istitutotumori.mi.it; Barbara Frigerio - Barbara.Frigerio@istitutotumori.mi.it; Paolo Lusso - plusso@niaid.nih.gov; Luca Mollica - l.mollica@hsr.it; Lucia Lopalco - 1.lopalco@ hsr.it

* Corresponding author
\end{abstract}

Published: 28 November 2009

Journal of Translational Medicine 2009, 7:10I doi:I0.1186/1479-5876-7-10I
Received: 18 August 2009

Accepted: 28 November 2009

This article is available from: http://www.translational-medicine.com/content/7/I/IOI

(C) 2009 Burastero et al; licensee BioMed Central Ltd.

This is an Open Access article distributed under the terms of the Creative Commons Attribution License (http://creativecommons.org/licenses/by/2.0), which permits unrestricted use, distribution, and reproduction in any medium, provided the original work is properly cited.

\begin{abstract}
HIV-I exposure causes several dramatic unbalances in the immune system homeostasis. Here, we will focus on the paradox whereby CD4 specific autoimmune responses, which are expected to contribute to the catastrophic loss of most part of the $T$ helper lymphocyte subset in infected patients, may display the characteristics of an unconventional protective immunity in individuals naturally resistant to HIV-I infection. Reference to differences in fine epitope mapping of these two oppositely polarized outcomes will be presented, with particular reference to partially or totally CD4-gp I 20 complex-specific antibodies. The fine tuning of the anti-self immune response to the HIV-I receptor may determine whether viral exposure will result in infection or, alternatively, protective immunity.

Along this line, an efficacious anti-HIV strategy can rely on the active (i.e., through immunization) or passive targeting of cryptic epitopes of the CD4-gp/20 complex, including those harboured within the CD4 molecule. Such epitopes are expected to be safe from genetic drift and thus allow for broad spectrum of efficacy. Moreover, since these epitopes are not routinely exposed in uninfected individuals, they are expected to become targets of neutralizing antibodies or other specifically designed molecules only after viral exposure, with a predictable low impact in terms of potentially harmful anti-CD4 self-reactivity.

The experimentum naturae of naturally resistant individuals indicates a strategy to design innovative strategies to neutralize HIV-I by acting on the sharp edge between harmful and protective selfreactivity.
\end{abstract}




\section{The paradox of CD4 T cell depletion in HIV-I infection}

Immune abnormalities are common features of both HIV infection and autoimmune diseases. The depletion of the CD4 T lymphocytes is the hallmark of the progression of HIV infection and, in the absence of antiviral treatment, the main contributor to the development of opportunistic infections and ultimately to the death of the majority of infected patients.

CD4 T lymphocytes physiologically play a central role in orchestrating the whole immune response, including the humoral and the cellular arms of acquired immunity against pathogens. Thus, it could be theoretically expected that a profound inhibition of immune cell activation would go together with CD4 cell death in HIV-1 infected persons. In contrast, levels of immune activation, as assessed by proportions of CD38+ DR+ T cells and serum concentrations of $\beta 2$ microglobulin are closely correlated with disease progression and actually appear more accurate disease predictors than CD4 cell counts or viral load. HIV-1 infection leads to sustained activation of many key components of the immune system even in the very early stages and this is likely a fundamental mechanism for the ultimate collapse of immunity [1]. On the other hand, the natural host of SIV infection, sooty mangabeys, do not experience immune activation despite high levels of viral replication and this condition is associated with the absence of disease [2]. Similarly, the majority of HIV-2infected subjects who remain free from HIV-induced immune suppression show negligible immune activation, whereas immune activation in progressor subjects with HIV-2 is comparable to that seen in HIV-1 infection [3]. In this scenario, the immune response to self antigens has often been alleged to play a detrimental role, by acting as an effector mechanism which indeed could explain how the relatively limited numbers of CD4 T cells actually infected by HIV-1 could bring to the catastrophic loss of this cell type during disease progression.

In particular, autoimmunity could contribute to impair CD4 T cell functions in HIV-1 infected persons via reactivity to the CD4 molecule itself. Indeed, in a pilot study by Keiser et al. [4] and in our own experience (S. Burastero, personal observation) anti-CD4 antibodies were found 90 to 540 days before the appearance of antibodies to HIV-1 in exposed individuals, suggesting that they may play a detrimental role since the first stages of HIV-1 infection. A recent study mapped the earliest anti-gp120 binding antibody responses to include the third variable region (V3) and reported that antibodies specific for CD4-induced epitopes, the CD4 binding site, and the membrane proximal external region of gp41 were not identified among early anti-Env responses [5]. Moreover, Davis et al. reported that high-titre, broadly reactive V3-specific antibodies are among the first to be elicited during acute and early HIV-1 infection and following vaccination. However, these antibodies lacked neutralizing potency against primary HIV-1 viruses, which effectively shield V3 from antibody binding to the functional Env trimer [6]. In this context, dedicated parallel studies are needed to accurately define the timing of appearance of anti-CD4 antibodies, particularly to gp120-induced epitope, as compared to anti-Env antibodies

\section{Mechanisms for breaking of tolerance following HIV-I exposure 2a) Cell death and apoptosis}

Several mechanisms were studied, which could support the development of autoimmunity in HIV-1 infected persons. Oswald-Ritchter at al. proposed a specific susceptibility of regulatory T cells to HIV-1 infection [7] whereas Rawson et al. [8] focused on the increased tendency of CD4 T lymphocytes from infected individuals to undergo activation-induced death or apoptosis and demonstrated the subsequent presentation of remarkable amounts of self-epitopes. This second mechanism was found capable to break tolerance and trigger cytotoxic T cell-mediated autoreactivity towards several autoantigens, such as myosin, vimentin and actin [8], promoting the formation of autoreactive CD8 T cells. Apoptosis is an ordered state of cell death in which the structural components of the cell are carefully disassembled by the activity of a unique set of proteolytic enzymes, notably members of the caspase family [8]. The self-proteins broken down by caspases in a multitude of apoptotic cells can also prime cytotoxic T lymphocytes (CTLs) through subsequent proteasomal digestion and cross-presentation. Thus, the massive death and destruction of lymphocytes in HIV-1 infection could break tolerance to self-peptides and permits the generation of autoreactive CTLs responding to the cleavage products of apoptotic cells.

\section{2b) Immunodeficiency and autoimmune phenomena in lentiviral infection of non-human primates}

Both SIV-infected Rhesus macaques and Sooty Mangabeys, species from Africa are naturally infected with SIV, yet they do not display any detectable signs of immune deficiency or autoimmunity. On this basis, they have been used as models to explore the possible mechanism underlying the generation of autoimmune phenomena in HIV1 infected humans [9]. In one crucial observation based on ex vivo $\mathrm{CD} 4 \mathrm{~T}$ cell depletion, the availability of activated CD4+ T cells, rather than immune control of SIV replication, appeared the main determinant of viral load during natural SIV infection of Sooty Mangabeys [10]. Moreover, in blood and tissues of rhesus macaques inoculated with derivatives of the pathogenic SIVsmE543-3 or SIVmac239, phenotypic analysis of CD4(+) T cells demonstrated two patterns of depletion, primarily affecting either naïve or memory CD4(+) T cells [11], respectively. In this experimental setting, progressive decline of total 
CD4(+) T cells was observed only in those macaques with naïve CD4(+) T cell depletion and the level of autoreactive antibodies correlated with the extent of naive CD4(+) T cell depletion. These results suggest an important role of autoreactive antibodies and of naïve T cells in the CD4(+) $\mathrm{T}$ cell decline observed during progression to AIDS [11].

\section{2c) Cryptic epitopes and inter-molecular help can generate anti-CD4 auto-reactiviy}

An autoimmune cytotoxic T-cell response to the CD4 molecule was described in HIV-1 positive patients $[12,13]$. The unveiling of cryptic epitopes following internalization of CD4 in complex with gp120 was proposed to explain the pathogenesis of this phenomenon $[14,15]$. A further in vivo proof of principle of the importance of this mechanism was provided by Abulafia-Laid et al. [16], who showed the efficacy of T-cell vaccination against antiCD4 autoimmunity in a small sample of HIV-infected patients. Intracellular interactions of newly synthesized CD4 molecules with various HIV proteins may be the basis for the generation of various self-epitopes, which in the absence of HIV are ignored due to tolerance mechanisms. In fact, the formation of Env (gp160)-CD4 complexes in the ER can lead to their retention via binding to $\mathrm{Vpu}$, which re-direct them to degradation [17-20]. Similarly, Nef interaction with the cytoplasmic tail of membrane CD4 was reported to prompt its transport to degradation organelles [21]. Thus, autoimmunity to CD4 in HIV-1 infected patients is supported by several mechanisms associated with the generation of cryptic epitopes and to the activation of $\mathrm{T}$ cells not previously deleted by central tolerance during the maturation of the T cell repertoire.

An alternatively, not mutually exclusive hypothesis for the generation of anti-CD4 antibodies is the so-called "intermolecular help" phenomenon. This mechanism implies that gp120-specific T cells can help antibody production by CD4-specific B cells, which could recognize B-cell epitopes on a gp120-CD4 complex [22]. Although the in vivo relevance of this specific occurrence has never been established, it should to be considered as a reasonable possibility, reminiscent of the more general occurrence of redirected antigen-presentation, which follows presentation of antigens complexed with antibodies with different fine specificities $[23,24]$. However, this mechanism would imply that gp120-specific immunity would necessarily precede CD4-autoimmunity, whereas there is evidence in contrast to this scenario [4].

\section{3) Anti-CD4 antibodies in clinical practice: beyond immune suppression}

As expected from basic immunology notions, anti-CD4 antibodies have long been proposed and used as immune suppressors, e.g., in clinical trials for the treatment of human autoimmune diseases [25]. In early studies, antiCD4 mAbs were found capable to induce either cell depletion [26] or functional inactivation of $\mathrm{T}$ cells $[27,28]$, although activation of T-cell functions was also reported[29]. These divergent effects may explain the inconsistency in the clinical efficacy of different anti-CD4 mAbs particularly in the treatment of rheumatoid arthritis, namely a promising initial efficacy in open anti-CD4 trials $[30,31]$, subsequent discouraging double-blind clinical trials (reviewed in [32]), and, finally, a revitalization of the anti-CD4 treatment notion with new, humanized anti-CD4 mAbs [33]. Indeed, the usage of this approach has been hampered by the complexity of its effects on the immune system. For instance, it has long been known that anti-CD4 monoclonals are immune suppressive or tolerogenic depending on the circumstances of their administration [34-36]. Moreover, it is generally recognized that non-depleting monoclonal may be relatively more effective in tolerance induction, for instance in the treatment of rheumatoid arthritis [30], psoriasis [37], systemic lupus erythematosus [38] and multiple sclerosis [39], although only inconclusive and temporary symptom relief was achieved in open studies. The fine epitope specificity of anti-CD4 antibodies may play a role in this context, since in rat adjuvant arthritis the developmental pattern of arthritis differed substantially between three distinct monoclonals, two of them preventing, the third one accelerating the development of the disease [40]. The effect of each reagent on the signaling activated by CD4 via the p56 $6_{\text {lck }}$ interacting cytoplasmic tail is supposedly implicated in these differences.

In this context, the usage of human derivatives of mouse monoclonals allowed not only to reduce the generation of xenogeneic reactivity of rodent monoclonals, but also to modulate induced effector mechanisms. In engineered derivatives, the isotype used (e.g., IgG1 versus IgG4) has implication on complement fixation capability and on the binding to Fc receptors bearing cells, whereas variation in the number of binding sites (e.g., single chain constructs, FC fragments, etc.) implies modification of functional effects of the original reagent. Recently, a fully human anti-CD4 monoclonal antibody (HuMax-CD4) was tested in a multicenter, double blind, placebo-controlled, randomized clinical trial on 85 moderate to severe psoriasis patients, showing decreases in the psoriasis skin score, although this failed to reach statistical significance [41].

Further complexity to be considered when using in vivo CD4-interacting reagents derives from the fact that two sets of NFAT binding sites were identified in the HIV-1 long terminal repeat (LTR) promoter, and CD4 engagement can result on the $\mathrm{p} 56_{\mathrm{lck}}$ kinase dependent activation of both cellular transcription factors and HIV-1 LTR [42]. 
Thus, a signaling trigger via CD4 can activate both the endogenous and the retroviral NFAT family of transcription factors, simultaneously inducing both $\mathrm{T}$ cell activation and increased transcription of the viral genome [43]. This phenomenon was implicated to explain the observation that HIV-1-positive transplant recipients reduced viral burden during treatment with cyclosporin A (CsA) [44], a potent inhibitor of these transcription factors. Moreover, CD4 dimerization occurs when CD4 membrane cell density exceeds $10^{5}$ per cells, involves D4-D4 domain interactions and per se triggers auto-phosphorylation and $\mathrm{T}$ cell activation [45].

Thus, the effect of anti-CD4 in human therapy is far from being a straightforward immune suppression and is influenced by so different factors as epitope specificity, isotype and number of binding sites.

Recently, one anti-CD4 antibody (ibalizumab) which does not induce any relevant immune suppressive effect in vitro or in vivo was tested in phase II clinical trials, in the form of human IgG4 derivative, and appeared a promising tool to block HIV-1 infection without inducing any immunologically relevant side-effect $[46,47]$. This molecule recognizes a CD4 D2 epitope and does not significantly interferes with HIV-1 docking on the cell membrane. The anti-viral activity of ibalizumab is explained as a consequence of the interference on conformational changes taking place on the cellular HIV-1 receptor at the post-binding level [48].

\section{4) Antibodies to the CD4-gp I 20 complex}

Following CD4-gp120 interaction, a sequence of preordered conformational changes takes place on both moieties of the complex. These conformational modifications are non-optional events, which allow gp120 interaction with coreceptor and prompt membrane fusion and viral entry into the cells. From the immune system perspective, this conformational flexibility generates a series of transitorily expressed antigenic determinants, which re-design the epitopic make up of interacting moieties.

Along this line, a complementary and reciprocal observation came from a recent study focused on alterations in the antigenicity and immunogenicity of gp120 when complexed with monoclonal antibodies specific for the CD4 binding site of gp120 [49]. Results indicated that these antibodies enhanced production of anti-gp120 antibodies directed particularly against the V3 region[49]. These data further support the notion that immune responses can be induced specifically against unique epitopes created upon the interactions of CD4 with gp120, with monoclonal antibodies, or other ligands.

The binding of gp120 to CD4 involves a well-defined site within the first Ig-like domain of CD4 (CD4 D1) [50]. The
Phe43 CD4 residue plays a non-optional role in this crucial interaction [51] by docking into a conserved hydrophobic pocket, a discontinuous region at the interface between the inner and the outer domain of gp120 [52]. On the other hand, the lateral face of the D1 CD4 domain is implicated in MHC-class II interaction, which physiologically provides an activation signal and plays a key role in the physiological and pathological T lymphocyte functions [53].

Notably, the OKT4A monoclonal antibody specifically binds to the gp120 binding site of CD4, and displays, as expected, a remarkable anti-HIV activity in vitro. However, this reagent is also extremely immune suppressive due to interference on the physiological CD4 function. CD4 induced (CD4i) are those epitopes, which are exposed on the gp120 molecule after binding to the cellular receptor. All known CD4i antibodies recognize a common, conserved gp120 element overlapping the binding site for the CCR5 chemokine receptor [54]. Recently, we characterized a gp120 neutralization epitope, recognized by the D19 murine monoclonal antibody, which is differentially accessible in the native HIV-1 Env according to its coreceptor specificity [55]. In CCR5-restricted (R5) isolates, the D19 epitope was invariably cryptic, although it could be exposed by the addition of soluble CD4; epitope masking was dependent on the native oligomeric structure of Env, since it was not observed with the corresponding monomeric gp120 molecules. By contrast, in CXCR4using strains, the D19 epitope was constitutively accessible. In accordance with these results, R5 isolates were resistant to neutralization by D19, becoming sensitive only upon addition of sCD4, whereas CXCR4-using isolates were neutralized regardless of the presence of sCD4 [55]. Taken together, these observations can be deciphered in evolutionary term by saying that CD4-induced changes in gp120 conformation are functionally crucial for HIV-1 entry, and illustrates a viral strategy for sequestering the chemokine receptor-binding region of gp120 away from the attacks of the humoral immune response [56].

In a reciprocal fashion, similar observations can be applied to the CD4 receptor. Complex specific epitopes on the CD4 moiety have been identified with partially or totally complex-specific monoclonals antibodies, which do not interfere with the CD4-Env complex formation, such as CG10 [57] and antibody 55 [58], both mapping to the second Ig-like CD4 domain. We recently generated an anti-D2 CD4 monoclonal antibody (DB-81) [59,60] not interfering with gp120 binding and with a binding affinity around 700 times higher for CD4 complexed to gp120, as compared to CD4 (Burastero S, Lusso P, et al., in preparation). Notably, CG10 is weakly interfering with membrane fusion and HIV replication [57], whereas antibody 55 [58] and DB-81 react with both membrane- 
bound and solid-phase coated recombinant CD4 and display a broad spectrum of neutralization, suggesting that little differences in the fine specificity may imply relevant impact on the capability to interfere with the chain of events which follows viral docking on the cell membrane.

A visual representation of conformation-specific epitopes generated following CD4-gp120 interaction is depicted in figure 1, where the binding of some of the above quoted monoclonals is represented. In Table 1 the basic mechanisms of protection by representative CD4 binding monoclonals are listed.

\section{5) Fine specificity of anti-CD4 antibodies in HIV- I exposed individuals with different susceptibility to HIV infection}

It has long been known that autoimmune responses towards CD4 detected in HIV-1 infected individuals are produced (by the breaking of immune tolerance) which seem to discriminate soluble versus cell associated CD4 antigens.

In fact, it was consistently reported that these antibodies bind to solid-phase recombinant $\mathrm{CD} 4$, but fail to recognize CD4 expressed on the surface of CD4+ lymphocytes or cell lines [61,62](Burastero, personal observations). These antibodies are mainly directed against a region of the viral receptor distinct from the virus-binding domain [63] and preferentially recognize epitopes masked by the physiological dimerization of CD4 on the cell membrane. This observation suggests that they are derived from such an extensive processing of the self antigen that hidden epitopes "emerged" on antigen presenting cells and were exposed efficiently enough to become the target of humoral immunity.
Consistently with these findings, extensive epitope scanning mapped CD4-specific T cells in HIV-1 positive individuals to any of the four CD4 domains [64]. In contrast, the little proportion of CD4-reacting IgG from healthy individuals are specific for epitopes of extracellular CD4 domains (ibid.).

Recently, Denisova et al. [45] reported that immunization of hu-CD4 C57Black/6J mice with HIV-1 gp120(451) complexed with its receptor protein produced, in the tolerogenic hu-CD4 transgenic background used to mimic the human situation, two anti-CD4 monoclonal antibodies, designated $\mathrm{T} 6$ and $\mathrm{T} 9$, mapping to the D3-D4 domains and recognizing soluble but not membrane associated CD4. These antibodies were capable to compete with anti-CD4 antibodies detected in HIV-1 infected people.

In contrast to this situation, a surprise came from individuals with natural resistance to HIV-1 infection. Far from being immunologically non-reactive, these HIV-exposed, uninfected subjects (ESN) display several unconventional autoimmune traits, including the distinctive reactivity towards the CD4 molecule [65]. An inter-molecular help mechanism could explain the breaking of tolerance and the switch to the IgG isotype of these antibodies [66]. Also newborn babies from seropositive mothers were found to display this autoimmune trait, which disappeared following spontaneous viral clearance [67]. These antibodies are likely part of a more general anti-cell immunity, including specificities to CCR5, the HIV- coreceptor [68].

Notably, anti-CD4 antibodies in ESN subjects bind to both membrane and soluble CD4 and have syncytium inhibiting activity [65]. The distinct fine specificity of anti-

Table I: MECHANISMS OF HIV-PROTECTION BY ANTI-CD4 ANTIBODIES

\begin{tabular}{llll}
\hline I) interference with $\mathbf{g p}$ / 20 binding & \\
\hline Antibody & Binding site & Binding to CD4-gp/20 complex & Characteristics \\
\hline OKT4a[76] & First CD4 domain & Does not occur due to epitope masking & $\begin{array}{l}\text { Difficult to generate in vivo } \\
\text { Immune suppressive }\end{array}$ \\
\hline
\end{tabular}

2) interference with the sequence of conformational modifications subsequent to gp/ 20 binding and permissive to coreceptor binding and membrane fusion

\begin{tabular}{llll}
\hline Antibody & Binding site & Binding to CD4-gp/20 complex & Characteristics \\
\hline Ibalizumab[46] & Second CD4 domain & $\begin{array}{l}\text { Equivalent binding to free and complexed } \\
\text { CD4 }\end{array}$ & Non immune suppressive \\
\hline DB-8I[59,60] & Second CD4 domain & Increased binding to complexed CD4 & a) Non immune suppressive; \\
& & & b) Fine specificity shared by ESN individuals
\end{tabular}




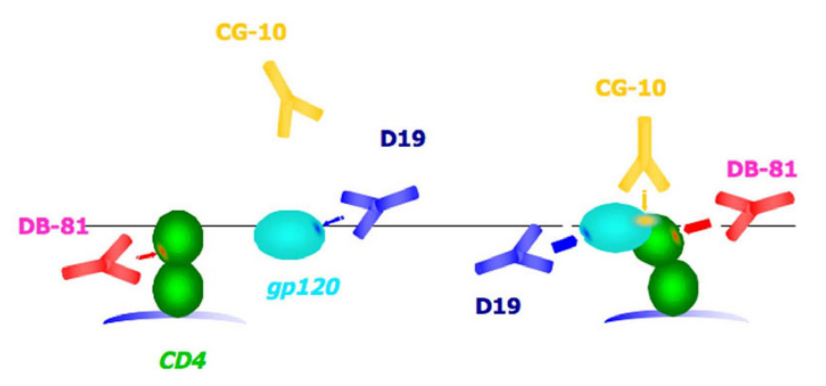

Figure I

Schematic representation of the interaction between CD4 and gp I 20, with reference to the formation of new epitopes. The indicated monoclonal antibodies are either exclusively (CGI0) or preferentially (DB-8I) binding to CD4 complexed to gp 20 (right part of the figure), as compared to CD4 only (left part of the figure). Similarly, the anti-gp I 20 D I 9 monoclonal antibody is represented, which binds with higher affinity to gp I 20 complexed to CD4, as compared to (R5-coreceptor restricted) gp 20 only. The affinities of the antigen-antibody interactions are proportional to the thickness of the arrow pointing to the epitope.

CD4 antibodies in exposed uninfected, naturally resistant, versus HIV-1 infected people was later confirmed in a larger cohort of individuals, where a clear-cut prevalence of complex-specific antibodies in the former was reported, suggesting a possible protective role [68]. This notion was also supported by preliminary observations with antiCD4 sera form long-term non-progressor patients [69].

Thus, anti-CD4 antibodies in ESN subjects are one among several signs of unconventional immunity, which were described in HIV-1 resistant individuals [70]. We speculate that specificity to the first two domains of membrane CD4, with particular reference to strictly conformationdependent epitopes, and including those, which are preferentially expressed after gp120 binding may be associated with a non-harmful and potentially protective humoral anti-HIV-1 autoimmune response.

Further studies are needed to characterize anti-CD4 antibodies fine specificities in healthy subjects, with or without HIV- exposure, and to determine their HIV-1 inhibitory capability.

Molecular structure analysis of free versus unbound CD4 may be helpful in shedding light on the above reported observations. Here, the two structures backbones were aligned and they resulted to be almost completely overlapping (Root Mean Square Distance < $0.7 \AA$ ). C-alpha atoms B-factors were then extracted from the PDB files of the compared structures (accession numbers 3CD4 and 2NXY for CD4 and CD4-gp120 complex, respectively) as a measure of local backbone mobility [71](Figure 2). The first CD4 domain did not display significant variations of local backbone mobility with the expected exception of the region in close contact with the surface of gp120. In contrast, the second domain displayed large variations which mapped the majority of the structure (Figure 3). This result suggests that the D2 CD 4 domain significantly reduces its local flexibility, despite the fact that it is not directly involved in binding, whereas the D1 CD4 domain remains virtually unaltered in its local mobility. Thus, it appears that the conformation of the membrane molecule serving as viral receptor has a defined degree of flexibility of solvent-exposed determinants, which is decreased following ligand binding. This decrease occurs not only, as expected, in the direct proximity of the binding site, but also in extended portions of the second CD4 domain.

In order to further highlight these local differences, in figure 4 the variations of dihedral angles ( $\Phi$ and $\Psi$ ) between the bound and the free state are plotted against the single residues whose local geometry is influenced by the binding of the two moieties.

The pheomenon of complex-dependent conformational variations may be exploited to augment the chances of inhibiting viral entry by increasing the opportunity for

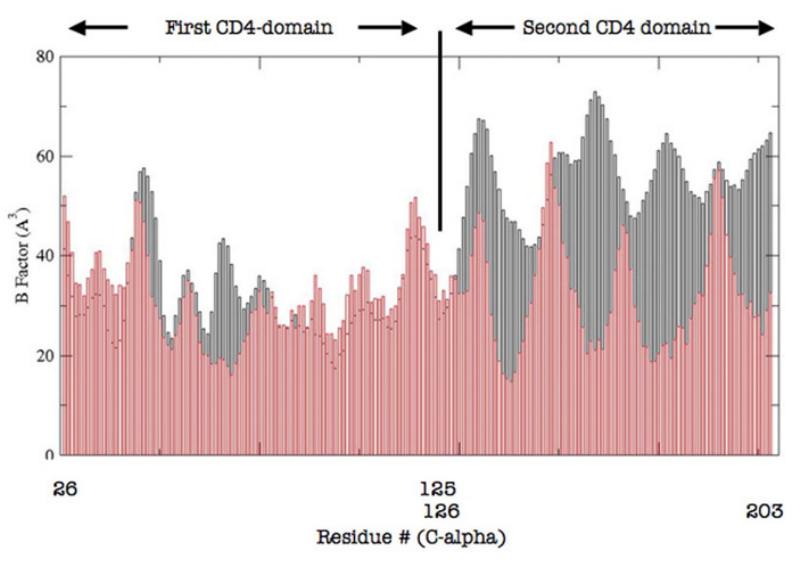

\section{Figure 2}

B factors (as a measure of local backbone mobility, on the $y$-axys) of C-alpha atoms for the free (gray) and the gp I 20-complexed (red) CD4 protein (Calpha residue numbering is on the $x$-axis, according to UniProtKB/Swiss-Prot P0I730). The first Ig-like V-type (residues 26 -- I25) and the second Ig-like C2-type I (residues 126 -- 203) were included in this analysis. Data were calculated from PDB files 3CD4 and 2NXY for free and complexed CD4, respectively. The third and forth domains were not considered due to the expected influence on $B$ factors of these portions of the molecule by physiological CD4 dimerization. 


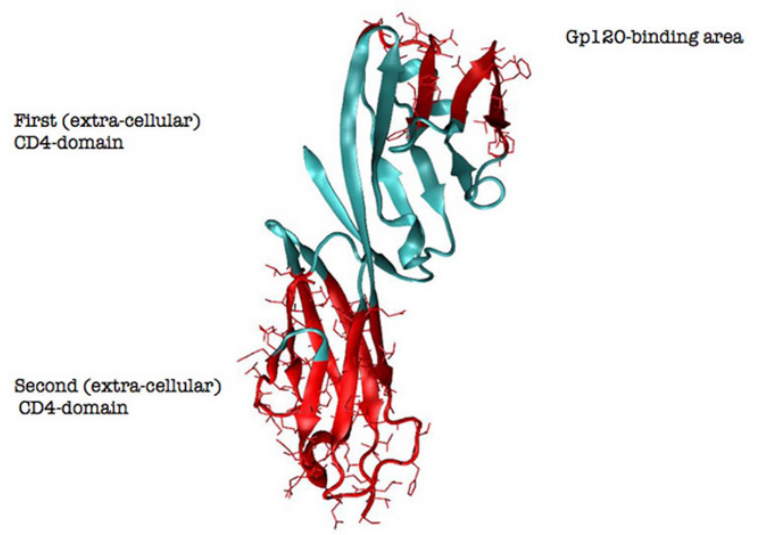

Figure 3

Regions of CD4 structure (within the first and the second CD4 domain) that display (in red) the greatest changes in C-alpha $B$ factor between the free form and the one complexed with gp I 20. The C-alpha B-factor was calculated as a measure of local backbone flexibility. binding to occur by strictly conformational antibodies, or derivatives thereof, specific to such protruding "stiffer" epitopes. Since such a locally rigid antigenic make up is by definition transient, and the corresponding set of epitope is limited, it may be in principle associated with an overall lower immunogenicity. However, available data on antiCD4 antibodies in ESN demonstrate that a proportion of individuals can indeed spontaneously produce antibodies with these fine specificities. These may pre-exist as the results of previous exposure to different (non HIV-related) antigenic stimuli, they may be natural antibodies with relatively low affinilty, and/or may be subjected to affinity maturation following HIV-1 exposure. The propensity to assume a different conformation as compared to the native one was also found associated to increased immunogenicity and antibody affinity in immunization experiments performed with CCR5-ECL-1 loop after alanine substitution [72]. In that context, this finding led us to hypothesize that flexibility of some conformed regions can change their status upon antigenic stimuli and prove helpful in enhancing immunogenicity and eliciting high affinity HIV protective antibodies.
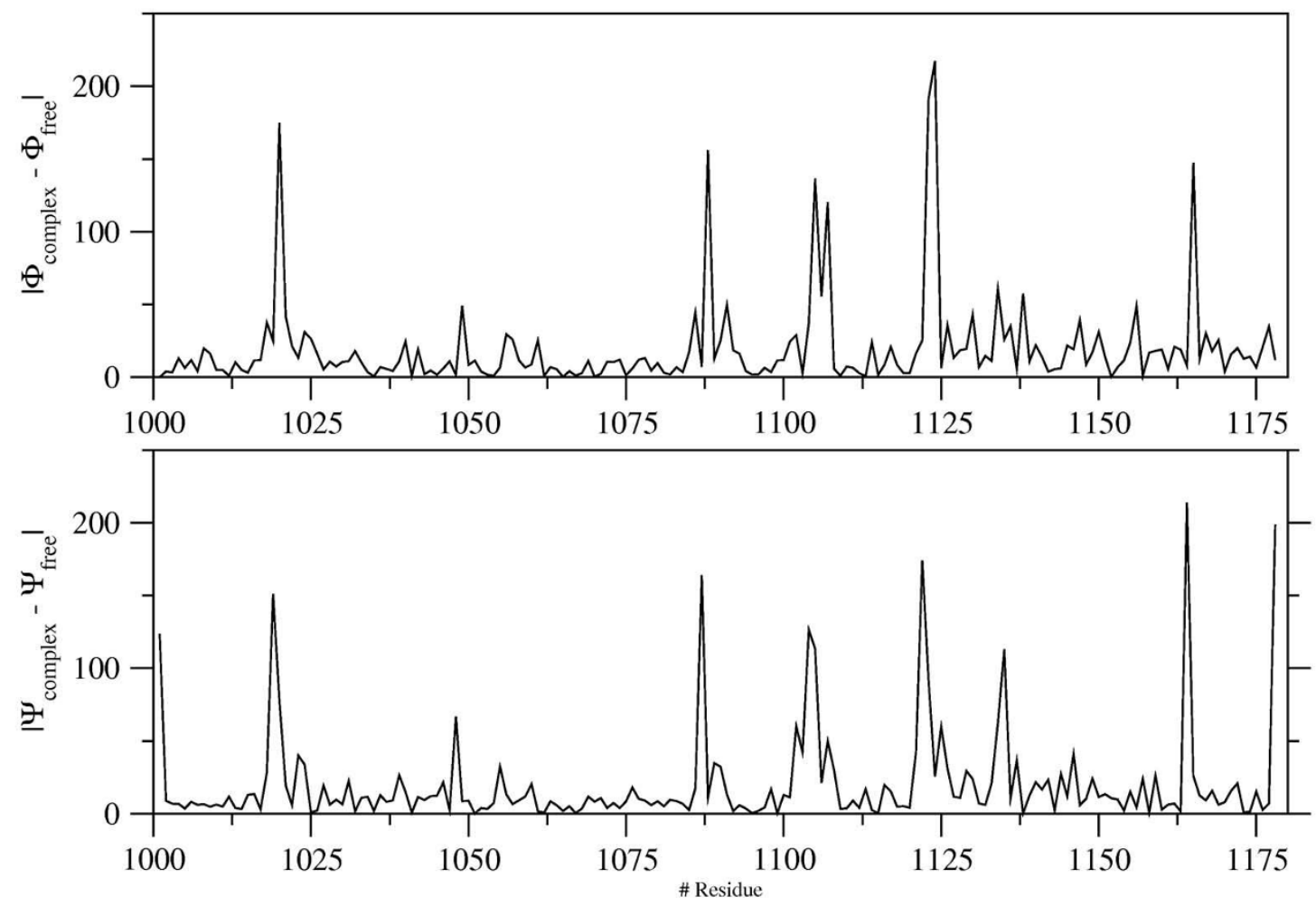

Figure 4

Local differences in the conformation of CD4 in the gp I20-bound versus free state. Absolute variations of dihedral backbone angles $\Phi$ (upper panel) ad $\Psi$ (lower panel) between bound and free CD4 structure are plotted on the $y$-axis against the single residues (on the $x$-axis) whose local geometry is influenced by the interaction between the two moieties. 


\section{Conclusion}

Individuals naturally resistant to HIV-1 infection represent an experiment of nature whose study has potential implication for the design of alternative immunological therapies of HIV-1 infection. Anti-CD4 antibodies are not subjected to the immune evasion, which characterize Envspecific immunity, nor to the generation of resistance, which impairs the efficacy of antiretroviral therapy with non-entry inhibitors. Thus, the possibility to elicit nonimmune suppressive, protective anti-CD4 immune responses or, alternatively, to use monoclonal antibodies or derivatives thereof, which will reproduce this activity may dramatically improve therapeutic options for HIV-1 treatment in the next few years.

A long-standing effort has been attempted to target conformation-specific epitopes, as a strategy to overcome the failure of conventional vaccination approaches to prevent HIV-1 infection [73-75]. The data we review here suggest that the fine characterization of crucial epitopes recognized by antibodies from ESN subjects will allow to increase the chances to successfully implement this strategy

\section{List of abbreviations \\ ESN: Exposed Sero-Negative.}

\section{Competing interests}

The authors declare that they have no competing interests.

\section{Authors' contributions}

SB and LL coordinated several studies on ESN subjects, aimed to characterize defined aspects of conventional and non-conventional immunity against HIV and the HIV receptor/co-receptor. PL and SB coordinated studies aimed to reproduce in a mouse-based animal model the generation of a humoral immunity mimicking some specific features of that observed in ESN individuals. LM performed structural biology studies to characterize epitopes recognized on the CD4 molecule by antibodies from ESN individuals and by mouse immunized with membranebound CD4-gp120 complex. MF and BF characterized the fine specificity and the binding characteristics $\left(\mathrm{K}_{\mathrm{on}}, \mathrm{K}_{\mathrm{off}}\right.$, affinity) of antibodies from ESN individuals and from mice immunized with membrane-bound CD4-gp120 complex. Moreover, MF and BF generated several human derivatives of single mouse monoclonals recapitulating these characteristics. All authors read and approved the final manuscript.

\section{Acknowledgements}

SB, LL and PL were funded by Istituto Superiore di Sanità, Rome, AIDS Program.
The funding body had no influence in the study design, collection, analysis and interpretation of data, writing of the manuscript and in the decision to submit the manuscript for publication.

\section{References}

I. Papagno L, Spina CA, Marchant A, Salio M, Rufer N, Little S, Dong T, Chesney G, Waters A, Easterbrook P, Dunbar PR, Shepherd D, Cerundolo V, Emery V, Griffiths P, Conlon C, McMichael AJ, Richman $\mathrm{DD}$, Rowland-Jones SL, Appay V: Immune activation and CD8+ T-cell differentiation towards senescence in HIV-I infection. PLoS Biol 2004, 2:E20.

2. Silvestri G, Sodora DL, Koup RA, Paiardini M, O'Neil SP, McClure HM, Staprans SI, Feinberg MB: Nonpathogenic SIV infection of sooty mangabeys is characterized by limited bystander immunopathology despite chronic high-level viremia. Immunity 2003, I 8:44|-452.

3. Rowland-Jones SL, Whittle HC: Out of Africa: what can we learn from HIV-2 about protective immunity to HIV-I? Nat Immunol 2007, 8:329-33l.

4. Keiser P, Keay S, Wasserman S, Wecksler W: Anti-CD4 antibodies are associated with HIV-I seroconversion and may be detectable before anti-HIV-I antibodies. The Multicenter AIDS Cohort Study. AIDS Res Hum Retroviruses 1992, 8:1919-1927.

5. Tomaras GD, Yates NL, Liu P, Qin L, Fouda GG, Chavez LL, Decamp AC, Parks RJ, Ashley VC, Lucas JT, Cohen M, Eron J, Hicks CB, Liao HX, Self SG, Landucci G, Forthal DN, Weinhold KJ, Keele BF, Hahn $\mathrm{BH}$, Greenberg ML, Morris L, Karim SS, Blattner WA, Montefiori DC, Shaw GM, Perelson AS, Haynes BF: Initial B-cell responses to transmitted human immunodeficiency virus type $I$ : virionbinding immunoglobulin $M$ (IgM) and IgG antibodies followed by plasma anti-gp4I antibodies with ineffective control of initial viremia. J Virol 2008, 82: I 2449-I 2463.

6. Davis KL, Gray ES, Moore PL, Decker JM, Salomon A, Montefiori DC, Graham BS, Keefer MC, Pinter A, Morris L, Hahn BH, Shaw GM: High titer HIV-I V3-specific antibodies with broad reactivity but low neutralizing potency in acute infection and following vaccination. Virology 2009, 387:4|4-426.

7. Oswald-Richter K, Grill SM, Shariat N, Leelawong M, Sundrud MS, Haas DW, Unutmaz D: HIV infection of naturally occurring and genetically reprogrammed human regulatory $\mathbf{T}$-cells. PLoS Biol 2004, 2:El98.

8. Rawson PM, Molette C, Videtta M, Altieri L, Franceschini D, Donato T, Finocchi L, Propato A, Paroli M, Meloni F, Mastroianni CM, d'Ettorre G, Sidney J, Sette A, Barnaba V: Cross-presentation of caspase-cleaved apoptotic self antigens in HIV infection. Nat Med 2007, I 3:1431-1439.

9. Ansari AA: Autoimmunity, anergy, lentiviral immunity and disease. Autoimmun Rev 2004, 3:530-540.

10. Klatt NR, Villinger F, Bostik P, Gordon SN, Pereira L, Engram JC, Mayne A, Dunham RM, Lawson B, Ratcliffe SJ, Sodora DL, Else J, Reimann K, Staprans SI, Haase AT, Estes JD, Silvestri G, Ansari AA: Availability of activated CD4+ $T$ cells dictates the level of viremia in naturally SIV-infected sooty mangabeys. J Clin Invest 2008, I I 8:2039-2049.

II. Kuwata T, Nishimura Y, Whitted S, Ourmanov I, Brown CR, Dang Q, Buckler-White A, lyengar R, Brenchley JM, Hirsch VM: Association of progressive CD4(+) T cell decline in SIV infection with the induction of autoreactive antibodies. PLOS Pathog 2009, 5:el000372.

12. Zarling JM, Ledbetter JA, Sias J, Fultz P, Eichberg J, Gjerset G, Moran PA: HIV-infected humans, but not chimpanzees, have circulating cytotoxic $T$ lymphocytes that lyse uninfected CD4+ cells. J Immunol 1990, I 44:2992-2998.

13. Kaufmann GR, Perrin L, Pantaleo G, Opravil M, Furrer H, Telenti A, Hirschel B, Ledergerber B, Vernazza P, Bernasconi E, Rickenbach M, Egger M, Battegay M: CD4 T-lymphocyte recovery in individuals with advanced HIV-I infection receiving potent antiretroviral therapy for $\mathbf{4}$ years: the Swiss HIV Cohort Study. Arch Intern Med 2003, 1 63:2187-2195.

14. Salemi S, Caporossi AP, Boffa L, Longobardi MG, Barnaba V: HIVgpI20 activates autoreactive CD4-specific $T$ cell responses by unveiling of hidden CD4 peptides during processing. J Exp Med 1995, I 81:2253-2257. 
15. Caporossi AP, Bruno G, Salemi S, Mastroianni C, Falciano M, Salotti A, Bergami N, Santilio I, Nisini R, Barnaba V: Autoimmune T-cell response to the CD4 molecule in HIV-infected patients. Viral Immunol 1998, I I:9-I7.

16. Abulafia-Lapid R, Mayan S, Bentwich Z, Keren-Zur Y, Avbramovitz Y, Cohen IR, Atlan $H$ : T-cell vaccination against anti-CD4 autoimmunity in HIV-I subtypes B and C-infected patients--an extended open trial. Vaccine 2005, 23:2। 149-2।53.

17. Schubert U, Bour S, Willey RL, Strebel K: Regulation of virus release by the macrophage-tropic human immunodeficiency virus type I AD8 isolate is redundant and can be controlled by either Vpu or Env. IVirol 1999, 73:887-896.

18. Fujita K, Omura S, Silver J: Rapid degradation of CD4 in cells expressing human immunodeficiency virus type I Env and Vpu is blocked by proteasome inhibitors. J Gen Virol 1997, 78(Pt 3):619-625

19. Kerkau T, Bacik I, Bennink JR, Yewdell JW, Hunig T, Schimpl A, Schubert U: The human immunodeficiency virus type I (HIV-I) Vpu protein interferes with an early step in the biosynthesis of major histocompatibility complex (MHC) class I molecules. J Exp Med 1997, 185: 1295-1305.

20. Paul M, Jabbar MA: Phosphorylation of both phosphoacceptor sites in the HIV-I Vpu cytoplasmic domain is essential for Vpu-mediated ER degradation of CD4. Virology 1997, 232:207-216.

21. D'Aloja P, Olivetta E, Bona R, Nappi F, Pedacchia D, Pugliese K, Ferrari G, Verani $P$, Federico M: gag, vif, and nef genes contribute to the homologous viral interference induced by a nonproducer human immunodeficiency virus type I (HIV-I) variant: identification of novel HIV-I-inhibiting viral protein mutants. J Virol 1998, 72:4308-4319.

22. Manca F, Seravalli E, Valle MT, Fenoglio D, Kunkl A, Li Pira G, ZollaPazner S, Celada F: Non-covalent complexes of HIV gp I 20 with CD4 and/or mAbs enhance activation of gp I 20-specific T clones and provide intermolecular help for anti-CD4 antibody production. Int Immunol 1993, 5: I I09-I I I7.

23. Manca F, Fenoglio D, Li Pira G, Kunkl A, Celada F: Effect of antigen/ antibody ratio on macrophage uptake, processing, and presentation to $T$ cells of antigen complexed with polyclonal antibodies. J Exp Med I99I, 173:37-48.

24. Manca F, Fenoglio D, Kunkl A, Cambiaggi C, Sasso M, Celada F: Differential activation of $T$ cell clones stimulated by macrophages exposed to antigen complexed with monoclonal antibodies. J Immunol 1988, I 40:2893-2898.

25. Hasler P: Biological therapies directed against cells in autoimmune disease. Springer Semin Immunopathol 2006, 27:443-456.

26. Moreland LW, Pratt PW, Bucy RP, Jackson BS, Feldman JW, Koopman WJ: Treatment of refractory rheumatoid arthritis with a chimeric anti-CD4 monoclonal antibody. Arthritis Rheum 1994, 37:834-838.

27. Jabado N, Pallier A, Le Deist F, Bernard F, Fischer A, Hivroz C: CD4 ligands inhibit the formation of multifunctional transduction complexes involved in T cell activation. J Immunol 1997, 158:94-103.

28. Tsygankov AY, Broker BM, Guse AH, Meinke U, Roth E, Rossmann $C$, Emmrich F: Preincubation with anti-CD4 influences activation of human T cells by subsequent co-cross-linking of CD4 with CD3. J Leukoc Biol 1993, 54:430-438.

29. Carrel S, Moretta A, Pantaleo G, Tambussi G, Isler P, Perussia B, Cerottini JC: Stimulation and proliferation of CD4+ peripheral blood T lymphocytes induced by an anti-CD4 monoclonal antibody. Eur J Immunol I 988, I 8:333-339.

30. Herzog C, Walker C, Muller W, Rieber P, Reiter C, Riethmuller G, Wassmer P, Stockinger H, Madic O, Pichler WJ: Anti-CD4 antibody treatment of patients with rheumatoid arthritis: I. Effect on clinical course and circulating $\mathbf{T}$ cells. J Autoimmun $1989,2: 627-642$.

31. Horneff G, Burmester GR, Emmrich F, Kalden JR: Treatment of rheumatoid arthritis with an anti-CD4 monoclonal antibody. Arthritis Rheum 1991, 34:129-140.

32. Epstein WV: Expectation bias in rheumatoid arthritis clinical trials. The anti-CD4 monoclonal antibody experience. Arthritis Rheum 1996, 39:1773-1780.

33. Choy EH, Connolly DJ, Rapson N, Jeal S, Brown JC, Kingsley GH, Panayi GS, Johnston JM: Pharmacokinetic, pharmacodynamic and clinical effects of a humanized IgGI anti-CD4 mono- clonal antibody in the peripheral blood and synovial fluid of rheumatoid arthritis patients. Rheumatology (Oxford) 2000, 39: I I39-1 I 46.

34. Qin SX, Cobbold S, Benjamin R, Waldmann H: Induction of classical transplantation tolerance in the adult. J Exp Med 1989, 169:779-794.

35. Gutstein NL, Seaman WE, Scott JH, Wofsy D: Induction of immune tolerance by administration of monoclonal antibody to L3T4. J Immunol I986, I 37: I I 27- I I 32.

36. Benjamin RJ, Waldmann $\mathrm{H}$ : Induction of tolerance by monoclonal antibody therapy. Nature 1986, 320:449-45I.

37. Morel P, Revillard JP, Nicolas JF, Wijdenes J, Rizova H, Thivolet J: Anti-CD4 monoclonal antibody therapy in severe psoriasis. J Autoimmun 1992, 5:465-477.

38. Hiepe F, Volk HD, Apostoloff E, von Baehr R, Emmrich F: Treatment of severe systemic lupus erythematosus with anti-CD4 monoclonal antibody. Lancet I991, 338:1529-1530.

39. Racadot E, Rumbach L, Bataillard M, Galmiche J, Henlin JL, Truttmann $M$, Herve $P$, Wijdenes J: Treatment of multiple sclerosis with anti-CD4 monoclonal antibody. A preliminary report on BF5 in 21 patients. J Autoimmun 1993, 6:77I-786.

40. Pohlers D, Schmidt-Weber CB, Franch A, Kuhlmann J, Brauer R, Emmrich F, Kinne RW: Differential clinical efficacy of anti-CD4 monoclonal antibodies in rat adjuvant arthritis is paralleled by differential influence on NF-kappaB binding activity and TNF-alpha secretion of T cells. Arthritis Res 2002, 4: I84-I89.

41. Skov L, Kragballe K, Zachariae C, Obitz ER, Holm EA, Jemec GB, Solvsten $H$, Ibsen HH, Knudsen L, Jensen P, Petersen JH, Menne T, Baadsgaard O: HuMax-CD4: a fully human monoclonal antiCD4 antibody for the treatment of psoriasis vulgaris. Arch Dermatol 2003, 139:1433-1439.

42. Di Somma MM, Majolini MB, Burastero SE, Telford JL, Baldari CT: Cyclosporin A sensitivity of the HIV-I long terminal repeat identifies distinct p56/ck-dependent pathways activated by CD4 triggering. Eur J Immunol 1996, 26:2 I8I-2I 88.

43. Cron RQ, Bartz SR, Clausell A, Bort SJ, Klebanoff SJ, Lewis DB: NFATI enhances HIV-I gene expression in primary human CD4 T cells. Clin Immunol 2000, 94:179-191.

44. Schwarz A, Offermann G, Keller F, Bennhold I, L'Age-Stehr J, Krause $\mathrm{PH}$, Mihatsch MJ: The effect of cyclosporine on the progression of human immunodeficiency virus type $I$ infection transmitted by transplantation--data on four cases and review of the literature. Transplantation 1993, 55:95-103.

45. Denisova G, Lideman L, Spectorman E, Abulafia-Lapid R, Burke M, Yust I, Gershoni JM: Characterization of new monoclonal antibodies that discriminate between soluble and membrane CD4 and compete with human anti-CD4 autoimmune sera. Mol Immunol 2003, 40:23I-239.

46. Jacobson JM, Kuritzkes DR, Godofsky E, Dejesus E, Larson JA, Weinheimer SP, Lewis ST: Safety, Pharmacokinetics, and Antiretroviral Activity of Multiple Doses of Ibalizumab (formerly TNX-355), an Anti-CD4 Monoclonal Antibody, in HIV-I Infected Adults. Antimicrob Agents Chemother 2008.

47. Boon L, Holland B, Gordon W, Liu P, Shiau F, Shanahan W, Reimann KA, Fung M: Development of anti-CD4 MAb hu5A8 for treatment of HIV-I infection: preclinical assessment in nonhuman primates. Toxicology 2002, 172:191-203.

48. Burkly LC, Olson D, Shapiro R, Winkler G, Rosa JJ, Thomas DW, Williams C, Chisholm P: Inhibition of HIV infection by a novel CD4 domain 2-specific monoclonal antibody. Dissecting the basis for its inhibitory effect on HIV-induced cell fusion. J Immunol 1992, 149:1779-1787.

49. Visciano ML, Tuen M, Gorny MK, Hioe CE: In vivo alteration of humoral responses to HIV-I envelope glycoprotein gp I 20 by antibodies to the CD4-binding site of gp I 20. Virology 2008, 372:409-420.

50. Kalyanaraman VS, Rausch DM, Osborne J, Padgett M, Hwang KM, Lifson JD, Eiden LE: Evidence by peptide mapping that the region CD4(8I-92) is involved in gp I 20/CD4 interaction leading to HIV infection and HIV-induced syncytium formation. J Immunol 1990, 145:4072-4078.

51. Moebius U, Clayton LK, Abraham S, Harrison SC, Reinherz EL: The human immunodeficiency virus gp 120 binding site on CD4: delineation by quantitative equilibrium and kinetic binding studies of mutants in conjunction with a high-resolution CD4 atomic structure. J Exp Med 1992, 176:507-517. 
52. Kwong PD, Wyatt R, Robinson J, Sweet RW, Sodroski J, Hendrickson WA: Structure of an HIV gp I 20 envelope glycoprotein in complex with the CD4 receptor and a neutralizing human antibody. Nature 1998, 393:648-659.

53. Gay D, Maddon P, Sekaly R, Talle MA, Godfrey M, Long E, Goldstein G, Chess L, Axel R, Kappler J, et al:: Functional interaction between human T-cell protein CD4 and the major histocompatibility complex HLA-DR antigen. Nature 1987, 328:626-629.

54. Xiang SH, Doka N, Choudhary RK, Sodroski J, Robinson JE: Characterization of CD4-induced epitopes on the HIV type I gp I 20 envelope glycoprotein recognized by neutralizing human monoclonal antibodies. AIDS Res Hum Retroviruses 2002, 18:1207-1217.

55. Lusso P, Earl PL, Sironi F, Santoro F, Ripamonti C, Scarlatti G, Longhi R, Berger EA, Burastero SE: Cryptic nature of a conserved, CD4inducible V3 loop neutralization epitope in the native envelope glycoprotein oligomer of CCR5-restricted, but not CXCR4-using, primary human immunodeficiency virus type I strains. J Virol 2005, 79:6957-6968.

56. Sullivan N, Sun Y, Sattentau Q, Thali M, Wu D, Denisova G, Gershoni J, Robinson J, Moore J, Sodroski J: CD4-Induced conformational changes in the human immunodeficiency virus type I gp I 20 glycoprotein: consequences for virus entry and neutralization. J Virol 1998, 72:4694-4703.

57. Gershoni JM, Denisova G, Raviv D, Smorodinsky NI, Buyaner D: HIV binding to its receptor creates specific epitopes for the CD4/ gp I 20 complex. FASEB J 1993, 7: I |85- I I87.

58. Celada F, Cambiaggi C, Maccari J, Burastero S, Gregory T, Patzer E, Porter J, McDanal C, Matthews T: Antibody raised against soluble CD4-rgp 120 complex recognizes the CD4 moiety and blocks membrane fusion without inhibiting CD4-gp I 20 binding. J Exp Med 1990, I72: I I43-II50.

59. Burastero SE: anti-human CD4-HIV-I-gp I 20 complex DB8I monoclonal antibody immunoglobulin kappa chain [Mus musculus]. 2008.

60. Burastero SE: anti-human CD4-HIV-I-gp /20 complex DB8 I monoclonal antibody immunoglobulin heavy chain [Mus musculus]. 2008.

61. Chams V, Jouault T, Fenouillet E, Gluckman JC, Klatzmann D: Detection of anti-CD4 autoantibodies in the sera of HIV-infected patients using recombinant soluble CD4 molecules. AIDS 1988, 2:353-361.

62. Sekigawa I, Groopmen JE, Allan JD, Ikeuchi K, Biberfield G, Takatsuki K, Byrn RA: Characterization of autoantibodies to the CD4 molecule in human immunodeficiency virus infection. Clin Immunol Immunopathol I99I, 58: I45-I53.

63. Kowalski M, Ardman B, Basiripour L, Lu YC, Blohm D, Haseltine W, Sodroski J: Antibodies to CD4 in individuals infected with human immunodeficiency virus type I. Proc Natl Acad Sci USA 1989, 86:3346-3350.

64. Abulafia-Lapid R, Keren-Zur Y, Yachnin Y, Atlan H: Major CD4 epitopes involved in anti-CD4 T-cell autoimmunity in HIV-I patients. Vaccine 2007, 25:3192-3199.

65. Burastero SE, Gaffi D, Lopalco L, Tambussi G, Borgonovo B, De Santis C, Abecasis C, Robbioni P, Gasparri A, Lazzarin A, Celada F, Siccard AG, Beretta A: Autoantibodies to CD4 in HIV type I-exposed seronegative individuals. AIDS Res Hum Retroviruses 1996, 1 2:273-280.

66. Furci L, Beretta A, Siccardi A, Lazzarin A, Confetti C, Magnani Z, Scarpellini $P$, Lopalco L, Burastero SE: Human immunodeficiency virus type I glycoprotein I 20-specific T lymphocytes provide intermolecular help for anti-CD4 autoantibody production in exposed uninfected subjects. AIDS Res Hum Retroviruses 1997, | 3:| |46|-|469.

67. Lopalco L, Magnani Z, Confetti C, Brianza M, Saracco A, Ferraris G, Lillo F, Vegni C, Lazzarin A, Siccardi AG, Burastero SE: Anti-CD4 antibodies in exposed seronegative adults and in newborns of HIV type I-seropositive mothers: a follow-up study. AIDS Res Hum Retroviruses 1999, 15:1079-1085.

68. Lopalco L, Barassi C, Paolucci C, Breda D, Brunelli D, Nguyen M, Nouhin J, Luong TT, Truong LX, Clerici M, Calori G, Lazzarin A, Pancino G, Burastero SE: Predictive value of anti-cell and antihuman immunodeficiency virus (HIV) humoral responses in HIV-I-exposed seronegative cohorts of European and Asian origin. J Gen Virol 2005, 86:339-348.
69. Burastero SE, Casoli C, Paolucci C, Breda D, Alberti C, Pastori C, Lopalco L: Anti-CD4-gp 120 complex antibodies in long-term non-progressors HIV-I positive patients: a role in slowing disease progression? Retrivirology 2006, 3(suppl I):36.

70. Lopalco L, Burastero SE: HIV-I and the self-nonself connection: how to sleep with the enemy and be much better off. AIDS Rev 2008, 10:162-171.

7I. Novotny J, Handschumacher M, Haber E, Bruccoleri RE, Carlson WB, Fanning DW, Smith JA, Rose GD: Antigenic determinants in proteins coincide with surface regions accessible to large probes (antibody domains). Proc Natl Acad Sci USA 1986, 83:226-230.

72. Pastori C, Clivio A, Diomede L, Consonni R, De Mori GM, Longhi R, Colombo G, Lopalco L: Two amino acid substitutions within the first external loop of CCR5 induce human immunodeficiency virus-blocking antibodies in mice and chickens. J Virol 2008, 82:4I25-4I34.

73. Kang CY, Hariharan K, Nara PL, Sodroski J, Moore JP: Immunization with a soluble CD4-gpl20 complex preferentially induces neutralizing anti-human immunodeficiency virus type I antibodies directed to conformation-dependent epitopes of gp I 20. J Virol 1994, 68:5854-5862.

74. Fouts TR, Tuskan R, Godfrey K, Reitz M, Hone D, Lewis GK, DeVico $\mathrm{AL}$ : Expression and characterization of a single-chain polypeptide analogue of the human immunodeficiency virus type I gpI20-CD4 receptor complex. J Virol 2000, 74: | |427-I | 436

75. Martin L, Stricher F, Misse D, Sironi F, Pugniere M, Barthe P, PradoGotor R, Freulon I, Magne X, Roumestand C, Menez A, Lusso P, Veas F, Vita C: Rational design of a CD4 mimic that inhibits HIV-I entry and exposes cryptic neutralization epitopes. Nat Biotechnol 2003, 21:7I-76.

76. Pulito VL, Roberts VA, Adair JR, Rothermel AL, Collins AM, Varga SS, Martocello C, Bodmer M, Jolliffe LK, Zivin RA: Humanization and molecular modeling of the anti-CD4 monoclonal antibody, OKT4A. J Immunol 1996, I 56:2840-2850.
Publish with BioMed Central and every scientist can read your work free of charge

"BioMed Central will be the most significant development for disseminating the results of biomedical research in our lifetime. "

Sir Paul Nurse, Cancer Research UK

Your research papers will be:

- available free of charge to the entire biomedical community

- peer reviewed and published immediately upon acceptance

- cited in PubMed and archived on PubMed Central

- yours - you keep the copyright
BioMedcentral 